\title{
El reportaje televisivo y sus interpretaciones de la realidad
}

\author{
Pastora MORENO ESPINOSA \\ Universidad de Sevilla \\ pamoreno@us.es
}

Recibido: 12 de diciembre de 2011

Aceptado: 17 de julo de 2012

\begin{abstract}
Resumen
La influencia de los medios audiovisuales es cada vez más importante y con el desarrollo de las nuevas tecnologías y de la comunicación vía Internet aún lo será más.

No obstante, y a pesar de su influencia, estos medios deben adaptarse a los nuevos tiempos. Como consecuencia de esta adaptación, la televisión tiende a modelos más lúdicos que informativos, donde cada vez más los programas de entretenimiento ocupan una parte importante de la parrilla. A tal efecto, estudiaremos un programa de TVE representativo del género reportaje, que nace hace ya más de dos décadas y cuya vocación es la de ir más allá de la simple actualidad, analizando la realidad con un tratamiento serio y riguroso.
\end{abstract}

Palabras clave: mass-media, escritura, redacción, titular, tema.

\section{The television reportage and its interpretation of reality}

\begin{abstract}
The influence of media is increasingly important and the development of new communication technologies and the Internet it will be even more. However, despite their influence, the media must adapt to new times. As a result of this adaptation, television tends to be more leisurely informative models, where more and more entertainment programs play an important part of television. To this end, we will study a program representative of the genus TVE report, rising for more than two decades and whose vocation is to go beyond the simple present, analyzing the reality with a serious and rigorous treatment.
\end{abstract}

Keywords: mass-media, writing, editing, title, subject.

Referencia normalizada: MORENO ESPINOSA, Pastora (2012): "El reportaje televisivo y sus interpretaciones de la realidad”. Estudios sobre el mensaje periodístico, vol. 18, núm. 2 (julio-diciembre), págs.: 823-832. Madrid, Servicio de Publicaciones de la Universidad Complutense.

Sumario: 1. Introducción. 2. Redacción, escritura y lenguaje periodístico en televisión. 2. Redacción, escritura y lenguaje periodístico en televisión. 3. Un ejemplo audiovisual ilustrativo. 4. Análisis. 5. Conclusiones. 6. Referencias bibliográficas.

\section{Introducción}

En la actualidad, los medios conocidos como "medios tradicionales", prensa, radio y televisión, están sufriendo los avatares de las nuevas tecnologías. La prensa escrita, con cientos de años de historia a sus espaldas, está siendo desplazada por el poder de Internet. La red ofrece de forma gratuita y sin tener que salir de casa productos con las mismas características que la prensa escrita, por lo que son ya muchos los usuarios que han optado por consultar desde el ordenador las noticias. Internet presenta además la ventaja de que las noticias son actualizadas al minuto, algo impensable en la prensa matutina.

La radio y la televisión, por su parte, presentan atractivos que le garantizan, al menos por el momento, la supervivencia. La influencia de los medios audiovisuales es cada vez más importante y con el desarrollo de las nuevas tecnologías y de la comunicación vía Internet aún lo será más. 
No obstante, y a pesar de su influencia, estos medios deben adaptarse a los nuevos tiempos.

Como consecuencia de esta adaptación, la televisión tiende a modelos más lúdicos que informativos, donde cada vez más los programas de entretenimiento ocupan una parte importante de la parrilla. Los modelos se repiten hasta la saciedad: Sálvame diario, Sálvame Deluxe y La Noria; Operación Triunfo, Gran Hermano, Mira Quien Baila... un largo etcétera de espacios vacíos de contenido informativo e, incluso, formativo.

En esa tendencia actual que algunos observamos con preocupación, existen programas más periodísticos o informativos. Estos a menudo son casos aislados y poco rentables, pero son sin duda una alternativa a los de entretenimiento.

En este sentido, la televisión pública nacional -a través de cualquiera de sus cadenas: La 1, La 2 o 24h- se erige como el baluarte de la televisión "de calidad", con numerosos programas que versan sobre el mundo de la lectura (Página 2), el cine (Días de Cine), la ciencia (Redes), la actualidad (Informe Semanal o 59 segundos), la realidad del Mundo (Documentos TV) o las minorías (En lengua de signos).

A tal efecto, estudiaremos el programa Documentos TV ${ }^{1}$ que nace el 29 de abril de 1986, hace ya más de dos décadas. Su vocación era la de ir más allá de la simple actualidad, analizando la realidad con un tratamiento serio y riguroso, trascendiendo de los hechos tal y como aparecen para buscar ese trasfondo que, muy a menudo, está oculto.

Este programa tiene carácter semanal y monográfico. Presenta además una doble vertiente: por un lado, emite reportajes de calidad elaborados por productoras internacionales y, por otro, produce sus propios documentales de investigación nacionales.

\section{Redacción, escritura y lenguaje periodístico en televisión}

La correcta utilización del lenguaje es básica para llevar a cabo una buena comunicación, sea en el campo que sea. Esta exigencia comunicativa toma además especial importancia en la labor periodística, donde la información requiere de una especial precisión en el lenguaje. No obstante, demasiado a menudo el periodista descuida la corrección lingüística.

El lenguaje periodístico, además de cumplir las normas gramaticales, ortográficas y léxicas de la lengua española, tiene unas características peculiares que deben tenerse muy en cuenta. Una parte de estas características es compartida entre unos soportes y otros. La claridad, la concisión, la sencillez... son propias de todo texto periodístico informativo, sea éste escrito, radiofónico o televisivo-.

Sin embargo, existen otra serie de rasgos muy concretos que dependen del medio en el que se trabaje. Aquí nos centraremos en el lenguaje audiovisual, ya que es de televisión de lo que hablamos en este estudio.

A la televisión como medio de grandes masas habría que sumar cada vez más en los últimos años la expansión de Internet. No obstante, a pesar del auge de las nuevas tecnologías, la imagen televisiva sigue teniendo un fuerte reclamo para los receptores. Se produce entre la televisión y la sociedad un juego de reflejos recíprocos. Así, la so-

Más información en la web de Documentos TV: http://www.rtve.es/noticias/documentos-tv/. 
ciedad bebe de la televisión que se va conformando a su vez a la medida de los gustos de la audiencia.

Además, los periódicos han adoptado formas televisivas, no sólo de imagen, sino también de redacción. En este sentido, son muchos los periodistas de prensa escrita que utilizan un lenguaje más simple y directo, un lenguaje caracterizado por las frases cortas y la voz activa, entre otros muchos rasgos.

Cada vez son más las personas que se informan sólo a través de la televisión. Esta capacidad de llegar a un gran público obliga al periodista a cuidar aún más el uso del lenguaje por un doble motivo. De un lado, un correcto uso del lenguaje facilita el flujo de la información. De otro, y no menos importante, la televisión marca modelos también lingüísticos por lo que tiene la responsabilidad de difundir el español más correcto posible.

De ahí deriva la preocupación expresada por la Real Academia de la Lengua Española. En el prólogo del Libro de Estilo de Canal Sur Televisión, Manuel Alvar miembro de la RAE- señala:

"La lengua, cualquier lengua, está en poder de los medios de comunicación. ¿Qué puedo hacer yo, profesor de lingüística, frente a la audiencia que atiende a un locutor? Son esos profesionales quienes van a crear buena parte de nuestro futuro de hispano hablantes. [...] Son los periodistas de la prensa, de la radio o de la televisión, quienes proyectan más sus modalidades; por tanto, responsables en mayor grado del deterioro o de la corrección" (Alvar, 1991).

En esa misma línea se ha expresado en numerosas ocasiones Lázaro CARRETER (2008) -quien fuera director de la Real Academia de la Lengua Española- a través de su Dardo en la palabra, libro en el que reflexiona a menudo sobre el mal uso que desde los medios se hace del lenguaje y cómo ese mal uso acaba calando de forma definitiva en la sociedad a la que se dirige. Especialmente destacado es para este autor el caso de los periodistas deportivos.

La corrección en el lenguaje no debe confundirse con el uso de términos incomprensibles para una parte importante de la audiencia. A menudo, la reflexión sobre el uso del lenguaje en la televisión ha llevado a muchos a argumentar que la televisión debe estar al alcance de todos. Pero, jes esto incompatible con el uso correcto de la lengua española? En ese sentido, el Libro de Estilo de Canal Sur (1991) indica que "hay que buscar siempre la frase o palabra que la audiencia comprenda con mayor facilidad. El lenguaje debe ser simple y directo, lo que no quiere decir ramplón, mal escrito o leído".

El periodista televisivo cuenta además con una dificultad añadida: la inmediatez. En televisión la actualidad informativa manda, y esta rapidez es a menudo enemiga del correcto uso del lenguaje. Nos referimos a los espacios informativos, no a programas más en profundidad como pueden ser los formatos semanales. Al menos dos motivos explican la inexactitud de la redacción: la rapidez con que se redacta y el poco tiempo con que el periodista cuenta para conocer en profundidad el tema y poder comunicarlo con precisión. Existen numerosas normas de redacción para televisión.

El trabajo de un buen periodista es muy similar en uno u otro medio. Sin embargo, para televisión existe una salvedad: el apoyo de la imagen. Esto obliga al periodista de televisión a estar preparado para conocer cómo debe reaccionar ante las situacio- 
nes, necesitando para ello un manejo fluido y natural del lenguaje. Existen además otros rasgos específicos y condicionantes de la comunicación audiovisual: el tiempo, la hora de emisión, el área de señal y el culto a la personalidad. Todos estos rasgos son comunes en la comunicación radiofónica.

Para Giovanni SARTORI (1998), "nos encontramos en plena y rapidísima evolución multimedia. Un proceso que tiene numerosas ramificaciones -Internet, ordenadores personales, ciberespacio- y que, sin embargo, se caracteriza por un común denominador: tele-ver, y como consecuencia, nuestro vídeo-vivir. [...] Centraremos nuestra atención en la televisión, y la tesis de fondo es que el vídeo está transformando al homo sapiens, producto de la cultura escrita, en un homo videns para el cual la palabra está destronada por la imagen”. Pero, ¿no ha sido siempre el hombre un homo videns? ¿Es realmente novedoso o la televisión sólo viene a responder a una característica intrínseca del ser humano?

Es por tanto la imagen el rasgo más diferenciador y característico de la televisión, y el redactor debe tenerla muy en cuenta a la hora de preparar y redactar su noticia.

La televisión es un agente formador que se infiltra en el hogar, apelando a las emociones, utilizando un lenguaje accesible -para el que no es necesaria la alfabetización, de fácil comprensión -para mayores y pequeños-, y cercano al espectáculo.

La relación entre las emociones y la televisión merece, por su relevancia, un espacio en este artículo. Según explica SEDEÑo VALDELlós en su trabajo "Emoción y hábitos de los niños frente a la televisión" (2006), la televisión expone mejor los sentimientos visibles debido a que las reacciones emocionales ocurren simultáneamente a otros hechos. La letra impresa, por su naturaleza secuencial y lineal, sólo puede presentar los pensamientos uno tras otro. Este poder que tiene la televisión puede constituir, en palabras de la profesora SEDEÑO VALDELLós (2006: 121), un riesgo tanto como un beneficio, ya que "la estimulación de las emociones dentro de una situación en la que no se producen consecuencias en el mundo real puede ocasionas una desensibilización emocional".

Otra de las características de la información televisiva es la gran variedad de códigos y subcódigos que conforman sus mensajes. Los códigos básicos son las imágenes, los sonidos musicales o ruidos y las emisiones verbales -elemento que nos interesa de forma muy especial en este trabajo-. Sobre estos códigos básicos se asientan una gran diversidad de subcódigos como son el deontológico, el estético, el erótico o el emotivo entre otros muchos.

Dentro de estos subcódigos -no poco importantes- juegan un papel muy considerable la imagen del presentador, que llega a tener para el espectador tanta importancia como el propio contenido del programa. Para los informativos, el vestuario debe ser discreto. En cambio, si se realiza por ejemplo un programa cultural dirigido a personas jóvenes, la indumentaria del presentador podrá ser -de hecho, deberá ser- más informal. Esto entronca además con la idea anteriormente señalada del presentador estrella, que presta su imagen al programa que dirige.

Una de las normas esenciales del lenguaje televisivo es la claridad del mensaje. El lenguaje debe ser claro y sencillo y deben utilizarse palabras de uso extendido sin caer en vulgarismos. Del mismo modo, las frases deben ser construidas en voz activa, con 
un desarrollo ordenado y sin frases subordinadas. Además, resultan innecesarios los paréntesis y las perífrasis, así como los puntos suspensivos ya que en ningún caso deben darse una información por sobreentendida.

Otra de las normas esenciales es que deben evitarse las cacofonías mediante el uso de la sinonimia. Además, deben evitarse repeticiones innecesarias de palabras que podrían ser sustituidas por sinónimos por tal de que el mensaje no suene tan repetitivo al oyente. Sin embargo, en algunos casos el periodista debe repetir una idea por tal de que el espectador no se pierda y como consecuencia, desfallezca su atención. Las muletillas son expresiones monótonas de las que también debe prescindirse. Del mismo modo, debe prescindirse de las abreviaturas y siglas a menos que resulten conocidas por la totalidad del público.

Existen otra serie de normas que también resultan de vital importancia para que el mensaje pueda ser captado y comprendido por el espectador. Una de ellas es evitar el uso. Otra de las normas es redondear las cifras con tal de que el oyente pueda comprenderlas teniendo en cuenta la fugacidad del mensaje

Por otro lado, hay que tener el máximo respeto al oyente y por tanto es incorrecto y de mal efecto que un presentador se dirija a algún reportero o enviado especial refiriéndose a él solamente por el nombre de pila. Por consiguiente, también hay que ofrecer a los oyentes el apellido. Igualmente es incorrecto llamarse de "tu" y cursi hacerlo de "usted", por lo que lo correcto es utilizar fórmulas de cortesía tales como "pedimos a nuestro corresponsal". Sobre este mismo aspecto, es también importante utilizar fórmulas como "buenas tardes" para iniciar una intervención y finalizarlas con fórmulas tales como "y esto es todo".

Todos los ciudadanos tienen derecho a una información veraz, total y exacta. Cuando se da una información televisiva la objetividad, la veracidad y parcialidad son premisas a tener en cuenta. Por tanto, la información debe aparecer sin comentarios propios, ni opinión y no hay que escribir nunca ni a favor, ni en contra. El propio oyente es quién, a través de los datos que se le ofrezcan, debe determinar la importancia del asunto. Sobre este respecto, las reglas de oro son:

1. Evitar el partidismo político.

2. Mantener la neutralidad ante las personas involucradas.

Por ese mismo motivo, también deben evitarse los adjetivos y los adverbios puesto que casi siempre son innecesarios y hacen que se pierda la objetividad.

\section{Un ejemplo audiovisual ilustrativo}

El reportaje es un género de moda, que comienza a copar los prime time televisivos y que poco a poco se hace un hueco entre las preferencias de la audiencia. Entretiene e informa pero, sobre todo, busca guiar con su interpretación a los ciudadanos perdidos en lo que supone la sobreexposición informativa de nuestro tiempo. Cada uno usa técnicas diferenciadas, marcadas por su estilo y por la aplicación de teorías muchas veces escritas para cada ocasión, pero, en general, abordan temas de interés social.

Documentos $T V$ se emitió por primera vez el 29 de abril de 1986, en una España con una democracia joven que aún no había cumplido la mayoría de edad. Gobernaba en aquella época el Partido Socialista Obrero Español, con Felipe González a la ca- 
beza. Desde entonces se han emitido ya más de mil programas, pero aún puede verse el sello que imprimió hace dos décadas Pedro Erquicia como director del mismo.

Documentos $T V$ nace con la emisión de documentales de prestigio producidos en el extranjero. Fue diez años después cuando comenzaría a apostar por la realización de trabajos propios siguiendo la línea de los anteriores. Una proporción de producciones de la casa que sigue aumentando incesantemente cada año, mostrando una apuesta clara por reflejar la realidad española. En su página oficial en Internet, describen abiertamente sus objetivos entre los que se encuentran "analizar la realidad con un tratamiento serio y riguroso, trascendiendo de los hechos tal y como parecen para buscar ese trasfondo que, muy a menudo, permanece oculto. Y todo esto a través de documentales sobre hechos reales de carácter monográfico y con una gran calidad".

Esto nos lleva a tener en cuenta el ánimo investigador de este programa, su intencionalidad de mostrar la realidad desde un ángulo nunca antes abordado. Su éxito se encuentra avalado por numerosos premios y, sobre todo, por la continuidad en la parrilla televisiva en un mercado donde la descorazonadora competencia deja atrás a todos los perros viejos de la pantalla. Y es que más de veinte años en antena son muchos años.

Desde 1997, Televisión Española ha decidido invertir en la producción de documentales de investigación propios con el fin de emitirlos en el marco de Documentos $T V$. Estos se alternan con la producción extranjera de la que ya se nutría. Así, la televisión pública ha conseguido insertar documentales de calidad y con una gran profundidad sobre hechos acontecidos en España. Son ya setenta y cuatro los documentales producidos desde el año en que Televisión Española decidió apostar por la recuperación de la producción española. Después de más de diez años de producciones propias el equipo ha adquirido amplia experiencia. No obstante, la mayoría de los documentales emitidos en Documentos $T V$ siguen siendo de producción ajena y versan sobre temas internacionales. El programa ofrece una enorme riqueza audiovisual con gran variedad de planos y emplazamientos de cámara. Son tan habituales los planos largos como los cortos, siempre con una cadencia y mayor presencia en determinados momentos de la narración. Así, por ejemplo, somos capaces de observar una consecución de numerosos planos generales, muy abiertos al inicio de los reportajes, planos sin resto humano, que pretende describir, contextualizar, ubicar al espectador. Todos ellos son planos que respetan una larga duración en el tiempo, comprendiendo que el espectador necesita más tiempo para su asimilación, debido al mayor número de elementos que lo componen. Bien es cierto que los planos generales aparecen indistintamente en movimiento o fijos, en forma de panorámicas o travellings, al igual que los planos medios. Esto demuestra la mayor libertad a la que se presta este tipo de género.

En lo referido a los planos medios suelen reservarse a las declaraciones de especialistas o protagonistas, no suelen tener mucha duración, en la mayoría de las ocasiones apenas duran tres segundos. Esto demuestra la agilidad que le imprime el programa a sus documentales y la gran cantidad de recursos que deben grabarse para un programa de una hora.

Cada declaración permanece en un plano fijo. Esto responde a una intención clara: fijar la atención del espectador en las palabras de la persona que habla. Un movi- 
miento puede distraer. La mayoría de estos planos medios corresponden al encuadre de personas, y es que un plano más general los desubicaría y descontextualizaría al espectador de lo que realmente se quiere contar. Una repetición que se puede también observar en la mayoría de los temas. Y es que debemos tener en cuenta que los documentales emitidos por este programa no responden a la misma productora, aunque siguen una narrativa de planos. Normalmente, los planos generales más amplios van seguidos de planos generales algo más cortos. Su función probablemente sea la de localizar y contextualizar para luego encuadrar la acción.

Quizá es en el uso del primer plano donde marcamos más las diferencias entre unos y otros documentales. Es aquí donde notamos que no todos corresponden a la misma forma de ver una misma realidad.

Mientras que algunos documentales nunca emplean el primer plano para las declaraciones de los distintos personajes que intervienen en el programa, otros lo emplean como un recurso habitual. Bien es cierto que alterar los planos de una entrevista otorga dinamismo, pero al mismo tiempo obliga al espectador a realizar un ejercicio extra. Depende de lo dinámico que queramos hacer el programa optaremos o no por esta técnica.

En el caso de Documentos TV, su misión no es únicamente escoger planos bonitos o planos impactantes, sino útiles, con un centro de atención claro, que configuran planos complementarios que refuerzan el contenido de lo que se está contando.

Sí existen las panorámicas y los travelling que pretenden llamar la atención, captar el interés del espectador. Sin embargo, no aparecen barridos. Es explicable la ausencia de este recurso ya que no transmiten información, confunden al espectador y únicamente tienen utilidad como transición.

Son frecuentes los cambios de enfoque. Son muy recurrentes para cambiar el centro de interés de una imagen de un objeto a otro de una persona a otra. Los zoom in son muy frecuentes también en momentos de acentuación de la intensidad dramática. La iluminación es un elemento clave en Documentos TV. Cada iluminación responde a una intención. Por supuesto, nada es aleatorio. La narración más brillante es aquella que hace atractiva lo menos interesante. En estos reportajes la presencia de un guión literario queda en un segundo plano. El narrador con una voz en off se limita a presentar los hechos y personajes que forman parte de la historia que está narrando. Ellos son los verdaderos conductores de la información. El locutor, que no es necesariamente el periodista, presenta datos necesarios para comprender el acontecimiento que se está dando a conocer. Presenta a los actores del relato, pero se limita a narrar aquello que es imprescindible para seguir la historia y que con los personajes, no puede.

Todos los reportajes se completan con las imágenes, las acciones, las entrevistas, unidas por los pilares del montaje y desarrollan una historia completa, una única idea, un tema central.

Documentos TV es una producción de Televisión Española, la televisión pública. A lo largo de la historia los vaivenes ideológicos que ha sufrido la cadena se han correspondido con los periodos donde se ubicaba un cambio de gobierno. Por eso, se considera que en estos momentos la línea que establece la televisión estatal está acorde con las ideas vertidas por el gobierno actual. Sin embargo, en temas de investigación, quizá es menos evidente ese tipo de posicionamiento ideológico. Lo importante de la 
selección de temas probablemente aquí no se encuentre en lo que se cuenta, sino en lo que se oculta, en lo que queda fuera del alcance de visión del gran público. Es manifiesto que en la elección de temas se oculta una agenda setting que puede estar marcada por los intereses políticos y económicos del momento. No se habla de crisis, tampoco de paro ni de terrorismo, problemas de la actualidad, que podrían ser mostrados desde otra perspectiva pero donde no interesa profundizar. Los temas sociales son especialmente tratados por este programa. Se narran temas de la cotidianidad, que muy probablemente afecten a cualquier individuo de la sociedad, cercanos y que por tanto llaman poderosamente la atención. El análisis del tipo de temas que se muestran en estos documentales es bastante complejo. Debemos tener en cuenta que muchos de ellos corresponden a producciones extranjeras.

El factor humano es fundamental en Documentos TV, con un estilo austero, sencillo, clásico. Así podríamos decir que el hecho de que Documentos TV, mantenga su cabecera durante tantos años ya es una seña de identidad. Su característica voz en off, la banda sonora que la acompaña o el cuidado montaje y calidad de sus productos informativos determinan un estilo sólido que se refuerza cada año.

Sobre el montaje, una vez estudiadas las imágenes cabe destacar que la mayoría siguen la lógica de continuidad de acción, movimiento o proceso. También se emplea mucho la del contraste y causa y efecto. $Y$ es que todos siguen una lógica, ningún plano va sucedido de cualquier otro aleatorio, todos encajan en un discurso. Aunque el género proporciona más libertad en el salto de un plano a otro, siempre suele realizarse una transición intermedia, no suele haber demasiados saltos de uno general a un detalle, casi siempre se pasa a uno medio. No olvidemos que la naturalidad es lo que impera. El paso de uno a otro a través del corte directo marcan transiciones sencillas y que ofrecen mayor realismo al espectador.

La escasa presencia de la voz en off podríamos decir que es la mayor característica estilística de este programa. Una voz omnisciente que es única durante todo el relato.

Acompasada por la banda sonora, siempre siguiendo el ritmo marcado por los planos y generando en el espectador sentimientos muy marcados. Siempre hay sonidos que acompañan al reportaje, incluso el propio silencio tiene un significado. La propia cabecera del programa parece sugerirnos interés, su ritmo rápido, sus letras desconocidas, parecen inducirnos, invitarnos a descubrir algo nuevo. Un hecho fundamental del montaje, que aviva su calidad y credibilidad es la presencia continua de sonido ambiente.

Claridad y simplicidad reinan en la locución de estos documentales. No existe un lenguaje rebuscado. La entonación, la dicción son perfectas, propias de un locutor profesional que, como se aprecia en los título de crédito, no es la misma persona que el redactor de la información, del periodista que da origen a la investigación periodística. Los dobles sentidos y las omisiones son escasos y se consideran involuntarias. Durante el desarrollo del reportaje, premia la concisión y la precisión, la premisa de no dejar nada a la libre interpretación del receptor.

Para finalizar, tenemos que añadir que Documentos $T V$ ha sido galardonado en los últimos años con diversos premios en reconocimiento a su buen hacer periodístico. 


\section{Análisis}

A continuación, destacamos un ejemplo ilustrativo: Afganistán, tras la pista del dólar. (Fecha de emisión: sábado, 1 de mayo de 2010. Cadena: TVE La 2. Hora: 22:30. Temática: Reconstrucción de Afganistán. Producción: Premières Lignes (Francia). Duración: 57 minutos. Dirección: Manuel Sánchez Pereira).

Sinopsis: La corrupción y el abuso de poder impiden que los fondos de ayuda a Afganistán alcancen su destino, lo que provoca una gran desconfianza entre la población.

Corría el mes de junio de 2008, cuando americanos, franceses y alemanes se reunían con el gobierno afgano de Karzai, para hacer entrega de veinte mil millones de dólares. Su destino, la construcción de escuelas y hospitales, pero también iban dirigidos a erradicar el tráfico del opio.

Ocho años después de la caída de los talibanes y con la ayuda internacional enviada a Afganistán, ni un solo colegio ha sido construido en Kabul y los hospitales están hechos una ruina. Sin embargo, un sector se encuentra en pleno desarrollo, el de la construcción de casas de lujo. El distrito de Sherpur es el feudo de los nuevos señores de Afganistán. Allí, donde se deberían haber construido viviendas sociales, se construyen palacios y villas que disponen de sus propios guardias de seguridad.

Afganistán, tras la pista del dólar muestra un conflicto, que las autoridades desearían ocultar: la guerra entre los grupos cercanos al poder y los miles de pobres, a los que se les derriban sus casas de toda la vida, en favor de las grandes mansiones de los corruptos, allegados al poder. Los que utilizan los dólares de la comunidad Internacional para sus propios intereses.

Afganistán es unos de los cuatro países más pobres del mundo. La heroína inyecta cada año cuatro mil millones de dólares en sus arcas y otros cuatro mil más proceden de la ayuda internacional. Este flujo masivo de dinero ha provocado la llegada de especuladores y con ellos, la corrupción y la evasión de fondos.

Estos argumentos, junto a la más absoluta ausencia del sentido de servicio público son los que están utilizando los talibanes para incrementar su influencia en la población. Entre los afganos se ha extendido la desconfianza respecto a las ayudas de reconstrucción del país, porque para ellos no ha quedado prácticamente nada. Y quizás esta situación sea clave para entender el ascenso de los rebeldes, no sólo en los territorios, sino en las mentes y en los corazones de los afganos.

Antes de comenzar el documental, y como es característico en Documentos TV, se procede a la presentación del mismo a través de una sinopsis -no demasiado breve-, previo a la cabecera. En este caso concreto, el resumen se caracteriza por su dinamismo, mezclando imágenes en movimiento de Afganistán -tanto de la riqueza más esplendorosa como de la pobreza- y de los líderes mundiales.

El documental está bien construido y, en nuestra opinión se trata de un buen trabajo periodístico. El lenguaje es cercano y el tema de gran interés, ya que introduce una realidad prácticamente desconocida en occidente: la del mal uso que en Afganistán se está haciendo del dinero que nuestros gobiernos aportaron para la reconstrucción del país.

En este caso, debido a la naturaleza temática -más vinculada con la actualidadgran parte de las imágenes son actuales y en vídeo, lo que aporta un mayor dinamismo 
a la pieza. La voz en off va guiando el reportaje, en el que se incluyen diversos totales. Resulta especialmente interesante escuchar la voz de los afganos, ya que pocas veces tenemos ocasión de oír sus versiones.

\section{Conclusiones}

El lenguaje de los reportajes es cercano y asequible. El uso de las imágenes también suele ser muy acertado, con un montaje pulcro y sencillo.

Por lo demás, el tono suele ser bastante objetivo. Se interpretan los hechos pero no se opina.

Y es que la libertad expresiva y técnica que proporciona el reportaje permite acercar la realidad de formas muy diferentes. Es evidente que la amplitud temporal de este género, mayor que la noticia, obliga a obtener una amalgama de planos para potenciar el interés del espectador. Indistintamente, la composición de planos corresponde a una misma intencionalidad. Así, ambos emplean el plano medio para ilustrar y contextualizar, mientras que el primer plano se utiliza para mostrar detalles, es de carácter aclaratorio. La diferencia más importante la podemos encontrar en el plano medio. Aunque ambos la emplean como estándar para la captación de declaraciones $\mathrm{Docu}$ mentos cuida muchísimo la localización de las personas que atestiguan, los ubica en un lateral, mientras que en los reportajes de Jon Sistiaga no importa dónde se sitúe, es indiferente la acción que se reproduzca detrás del personaje.

Una misma realidad puede contarse de muy diversas maneras. Los recursos disponibles, el tiempo, los condicionantes o la intencionalidad determinan en gran medida el producto informativo final. Un proceso de narrar que ha ido evolucionando con el paso del tiempo. En la actualidad los reportajes no sólo tienen que informar, hay que entretener y captar la atención de una generación de espectadores nacida en la era audiovisual y acostumbrada al visionado diario de programas informativos.

\section{Referencias bibliográficas}

ALVAR, Manuel (1991): Prólogo del Libro de Estilo de Canal Sur Televisión. RTVA.

CANAL SUR (1991): Libro de Estilo de Canal Sur Televisión. RTVA.

CASALS CARRO, María Jesús (2005): Periodismo y sentido de la realidad. Teoría y análisis de la narrativa periodística. Madrid, Fragua.

ESTEVE RAMÍREZ, Francisco y FERNÁNDEZ DEL MORAL, Javier (1999): Áreas de especialización periodística. Madrid, Fragua.

LÁZARO CARRETER, Fernando (2008): El dardo en la palabra. Barcelona, De Bolsillo.

SARTORI, Giovanni (1998): Homo videns. La sociedad teledirigida. Madrid, Taurus.

SEDEÑO VALDELLÓS, Ana María (2005): "Emoción y hábitos de los niños frente a la televisión". Comunicar: Revista científica iberoamericana de comunicación y educación, vol. 25, 2, noviembre.

VILALTA I CASAS, Jaime (2007): El reportero en acción. Noticia, reportaje y documental en televisión. Barcelona, Publicacions i Edicions. Universitat de Barcelona. 